\title{
Gemcitabine and oxaliplatin (GEMOX) in gemcitabine refractory advanced pancreatic adenocarcinoma: a phase II study
}

\author{
A Demols ${ }^{*, 1}$, M Peeters' ${ }^{2}$, M Polus ${ }^{3}$, R Marechal', F Gay', E Monsaert ${ }^{2}$, A Hendlisz ${ }^{4}$ and JL Van Laethem' \\ 'Department of Gastroenterology, Gl Oncology Unit, Erasme University Hospital, Route de Lennik 808, Brussels 1070, Belgium; ${ }^{2}$ Department of \\ Gastroenterology, UZ Gent, 9000 Gent, Belgium; ${ }^{3}$ Department of Gastroenterology, CHU Sart Tilman, 4000 Liège, Belgium; ${ }^{4}$ Department of \\ Gastroenterology, Institut Bordet, 1000 Brussels, Belgium
}

\begin{abstract}
Gemcitabine and oxaliplatin (GEMOX) are active as first-line therapy against advanced pancreatic cancer. This study aims to evaluate the activity and tolerability of this combination in patients refractory to standard gemcitabine (GEM). A total of 33 patients (median age of 57) were included with locally advanced and metastatic evaluable diseases, who had progressed during or following GEM

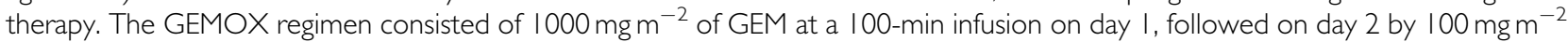
of oxaliplatin at a 2-h infusion; a cycle that was given every 2 weeks. All patients received at least one cycle of GEMOX (median 5; range I-29). Response by 3 I evaluable patients was as follows: PR: 7/3I(22.6\%), s.d. $\geqslant 8$ weeks: II/3I (35.5\%), s.d. <8 weeks: I/3I (3.2\%), PD: I2/3I (38.7\%). Median duration of response and TTP were 4.5 and 4.2 months, respectively. Median survival was 6 months (range $0.5-21$ ). Clinical benefit response was observed in 17/3I patients (54.8\%). Grade III/IV non-neurologic toxicities occurred in I 2/33 patients (36.3\%), and grade I, II, and III neuropathy in I7(5I\%), 3(9\%), and 4(I2\%) patients, respectively. GEMOX is a well-tolerated, active regimen that may provide a benefit to patients with advanced pancreatic cancer after progression following standard gemcitabine treatment.
\end{abstract}

British Journal of Cancer (2006) 94, 48I-485. doi:I0.1038/sj.bjc.6602966 www.bjcancer.com

Published online 24 January 2006

(c) 2006 Cancer Research UK

Keywords: advanced and metastatic pancreatic cancer; gemcitabine plus oxaliplatin; second line chemotherapy

Locally advanced and metastatic (MET) pancreatic adenocarcinomas carry a very poor prognosis. In patients treated with the standard palliative treatment gemcitabine (GEM), median survival still remains only 6 months (Burris et al, 1997). Over the last several years, many trials have been designed combining GEM with various other drugs to treat chemo-naive patients, with the aim to improve overall survival (OS) (Table 1). Unfortunately, none of the GEM-based combinations studied so far have reached that objective, with the exception of GEM plus Erlotinib, which showed a slight increase in OS to 6.4 months (Moore et al, 2005). However, some trials - mainly those using platinum based combinations have shown an increase in response rate (RR) and time to progression (TTP) (Table 1).

Unsurprisingly, the combination of GEM administered at a fixed dose rate (FDR) together with oxaliplatin (OX) is being tried more and more. It has become apparent that a FDR of $10 \mathrm{mg} \mathrm{m}^{-2} \mathrm{~min}^{-1}$ GEM is the optimal infusion speed to achieve the best conversion rate of active phosphorylated gemcitabine, providing a two-fold increase in intracellular gemcitabine triphosphate concentration (Tempero et al, 2003). Tempero et al have shown that when doing this, median survival was 8.0 months in the FDR arm $(P=0.013)$, and only 5.0 months in the standard arm (30-min infusion). In addition, at this infusion rate, GEM can be safely combined with

*Correspondence: Professor A Demols; E-mail: ademols@ulb.ac.be Received 3 October 2005; revised 19 December 2005; accepted 21 December 2005; published online 24 January 2006 oxaliplatin, with no overlapping toxicity. This combination appears to produce a sequence-dependent synergy of activity when exposing tumour cells firstly to GEM and then $24 \mathrm{~h}$ later with oxaliplatin (Faivre et al, 1999).

The combination of GEM and oxaliplatin (GEMOX regimen) has been reported by Louvet et al, to be active in first-line therapy against advanced and metastatic pancreatic cancer. GEMOX has also been shown to provide significantly better RR, clinical benefit response (CBR) and period-free survival (PFS) than GEM alone (Louvet et al, 2005). Furthermore, toxicity with this combination is limited (Louvet et al, 2002).

The GEMOX combination was shown to have a survival benefit of an additional 2 months, but this difference was not significant. Possible causes of this could be the lack of power in the statistical assumption, the inclusion of a high number of locally advanced diseases (LAD), and the proportion of second-line therapy using a platinum-based regimen.

However, in light of these interesting results, there are still no guidelines or recommendations for selecting treatment for patients progressing after GEM therapy; nor are there any reports of regimens with demonstrated activity that would enable one to justify one approach over another.

Consequently, we designed a multicentre phase II feasibility study whose primary aim was to evaluate activity and tolerability of the GEMOX regimen as second-line chemotherapy in gemcitabine-refractory advanced and metastatic pancreatic cancer. Secondary aims of the study included evaluation of TTP and overall survival. 
Table I Recent randomised phase III studies using gemcitabine-based combinations in first-line therapy

\begin{tabular}{|c|c|c|c|c|}
\hline Regimen & Authors & OS (months) & RR (\%) & TTP (months) \\
\hline $\begin{array}{l}\text { GEM } \\
\text { GEMOX }\end{array}$ & Louvet et al (2005) & $\begin{array}{l}7.1 \\
9.0\end{array}$ & $\begin{array}{l}16.7 \\
28.7 *\end{array}$ & $\begin{array}{l}3.7 \\
5.8\end{array}$ \\
\hline $\begin{array}{l}\text { GEM } \\
\text { GEM-DX }\end{array}$ & O'Reilly et al (2004) & $\begin{array}{l}6.2 \\
6.7\end{array}$ & $\begin{array}{l}6.3 \\
8.2\end{array}$ & $\begin{array}{l}3.8 \\
3.7\end{array}$ \\
\hline $\begin{array}{l}\text { GEM } \\
\text { GEM-CPTII }\end{array}$ & Rocha Lima et al (2004) & $\begin{array}{l}6.6 \\
6.3\end{array}$ & $\begin{array}{c}4.4 \\
\mid 6.1 *\end{array}$ & $\begin{array}{l}3.0 \\
3.4\end{array}$ \\
\hline $\begin{array}{l}\text { GEM } \\
\text { GEM-CDDP }\end{array}$ & Heinemann et al (2003) & $\begin{array}{l}6.0 \\
8.3\end{array}$ & & $\begin{array}{l}2.5 \\
4.6\end{array}$ \\
\hline $\begin{array}{l}\text { GEM } \\
\text { GEM-pemetrexed }\end{array}$ & Richards et al (2004) & $\begin{array}{l}6.3 \\
6.2\end{array}$ & $\begin{array}{l}9.1 \\
18.3 *\end{array}$ & $\begin{array}{l}3.6 \\
5.2 *\end{array}$ \\
\hline
\end{tabular}

Recent randomised phase III studies using gemcitabine-based combinations in first-line therapy. ${ }^{*} P<0.05$.

\section{PATIENTS AND METHODS}

\section{Patient eligibility}

The study has been approved by the ethics committees of each participating centre.

A total of 33 patients were eligible in four Belgian academic hospitals. Inclusion criteria were: histologically proven locally advanced or metastatic pancreatic adenocarcinoma, and progressive disease during or within 3 months of gemcitabine as first-line therapy or in adjuvant setting (including combination with radiation). The disease had to be measurable according to modified RECIST criteria (Therasse et al, 2000). All patients signed a written informed consent to participate, were over 18 years old, had a World Health Organization (WHO) performance status (PS) of 0,1 or 2 , and a life expectancy of more than six weeks (due to bad prognosis of the disease). Adequate bone marrow (ANC $\geqslant$ $1.5 \times 10^{9} \mathrm{~L}^{-1}$, platelets $\left.\geqslant 100 \times 10^{9} \mathrm{~L}^{-1}, \mathrm{Hb} \geqslant 9 \mathrm{~g} \mathrm{dl}^{-1}\right)$, liver function (AST, ALT $\leqslant 2 \times \mathrm{ULN}$, total bilirubin $\leqslant 1.5 \times \mathrm{ULN}$ ), and renal function (serum creatinin $\leqslant 2 \mathrm{mg} \mathrm{dl}^{-1}$ ) were required.

Previous or concomitant malignancy, cystic or neuroendocrine tumours, and peripheral neuropathy (regardless of origin) were considered as exclusion criteria.

At the time of inclusion, all patients underwent clinical examination. Weight, height and PS were carefully recorded, and abdominal CT, chest X-ray and plasma CA19.9 measurement were performed before GEMOX administration.

\section{Treatment plan}

GEMOX regimen (Louvet et al, 2002) consisted of $1000 \mathrm{mg} \mathrm{m}^{-2}$ of GEM at a 100-min infusion on day 1 (infusion rate $10 \mathrm{mg} \mathrm{m}^{-2} \mathrm{~min}^{-1}$ ), followed on day 2 by $100 \mathrm{mg} \mathrm{m}^{-2}$ of oxaliplatin at a 2-h infusion. This cycle was given every 2 weeks until progression of the disease. Oxaliplatin was provided by SanofiSynthelabo (Paris, France) on a compassionate use basis.

\section{Dose modifications}

Before each cycle, assessment of haematologic and nonhaematologic toxicities were performed using the NCI-CTC toxicity scale (version 2.0).
In cases of febrile neutropenia or bleeding due to thrombocytopenia, treatment was permanently withheld.

In cases of non-neurologic toxicity above grade (gr) 2, the entire next cycle was delayed until toxicity had declined to gr 2 or less. After recovery, subsequent doses were reduced as follows: GEM $800 \mathrm{mg} \mathrm{m}^{-2}$ at an $80-\mathrm{min}$ infusion and oxaliplatin $85 \mathrm{mg} \mathrm{m}^{-2}$ at a 2-h infusion.

If a gr 3 cumulative typical peripheral neuropathy appeared, oxaliplatin was discontinued; in the case of gr 2, the dose was reduced to $85 \mathrm{mg} \mathrm{m}^{-2}$. For laryngopharyngeal dysesthesia, oxaliplatin infusion was reduced and given $6 \mathrm{~h}-$ and eventually stopped if further symptoms occurred during the following cycles.

\section{Concomitant therapies}

During the entire treatment, patients could receive full supportive care: antiemetics (anti-5 $\mathrm{HT}_{3}$ ), steroids, analgesics, antibiotics, and acid-secretion inhibitors were permitted at the discretion of the physician in charge of the patient. No other chemo-, immuno- or experimental therapy was allowed during the study.

\section{Follow-up}

Until progression of the disease, Karnovsky Assessment (KA), physical examination, and blood analysis (haematology and chemistry tests) were performed before the administration of each cycle.

NCI-CTC toxicity scale (version 2.0) haematologic, nonhaematologic, and neurologic (Sanofi scale) toxicities were carefully recorded, as well as late toxicities, if any.

Clinical benefit was evaluated weekly, and was based on KS assessment, weight measurement, evaluation of pain intensity (using a visual analogue scale), and analgesic consumption. Patients were asked to fill out a daily diary, which was reviewed during each patient's weekly assessment.

Evaluation of the tumour response was performed every four cycles (or at anytime if there was clinical evidence of progression) using modified RECIST criteria. Treatment was stopped at progression of the disease.

Patients were followed until death. 


\section{Statistical analysis}

The number of the patients required for the study has been determined according to a two-stage Simon design. The target enrolment was estimated to be 33 patients, and all analyses were performed on the intention-to-treat population.

The minimum target activity level was $10 \%$ and early discontinuation of the trial was planned in the case of only two or fewer patients responding to treatment in the first 27 patients assessed. This reduces the chance of inadvertently rejecting a true response, or including a response rate below a certain standard. The trial design, therefore, ensures that (i) there is no more than a $10 \%$ chance that a treatment with a true response rate $(25 \%$ or more) is rejected, and (ii) that there is no more than a $10 \%$ probability that a response rate of $10 \%$ or less would be accepted.

The primary end point of the study was activity measured by RR and the feasibility of this second-line combination, where feasibility was defined as toxicity and tolerance.

In addition, as secondary end points, we evaluated the clinical benefit response, time to progression (TTP), and survival. Survival was calculated from the start of GEMOX administration until the death of the patient.

Statistical analysis was performed using the SPSS program (SPSS, Chicago, IL, USA).

\section{RESULTS}

\section{Patient's population}

A total of 33 patients ( 17 men and 16 women) with a median age of 57 (range 27-76), and WHO PS scores of $0 / 1 / 2(12,17$, and four

Table 2 Patients' demographics and prior therapy

\begin{tabular}{lc}
\hline Characteristics & $\boldsymbol{n}$ \\
\hline Men/women & $17 / 16$ \\
PS O/I/2 & $12 / 17 / 4$ \\
LAD/MET & $12 / 21$ \\
Adjuvant RT-CT & 6 \\
& \\
Prior therapy & 3 \\
RT-CT & 14 \\
GEM & 7 \\
GEM-PX & 2 \\
GEM-CDDP & 1 \\
Ralitrexed-GEM & 1 \\
\hline
\end{tabular}

Patients' characteristics and first line-therapy received. MET: metastatic disease; LAD locally advanced disease. patients, respectively) were included in a 12-month period. There were $12(35 \%)$ with locally advanced disease and $21(65 \%)$ with metastatic measurable disease. All 33 patients had previously progressed during or following GEM-based therapy (GEM alone: 14 patients, GEM + other drug: 10 patients, and GEM + radiation (RT): nine patients - including six adjuvant treatments after surgery, where all patients showing recurrence after adjuvant therapy (ADJ) discontinuation did so within 3 months). No patient received gemcitabine as a fixed dose rate infusion during the firstline treatment. Detailed patient demographics and prior therapy are listed in Table 2.

\section{Treatment completion and dose reductions}

All patients received at least one cycle of GEMOX. A total of 208 cycles were administrated, with a median number of five cycles given (range 1-29 cycles).

Eleven cycles were delayed due to gr 3 or 4 toxicities (described in Table 3). After recovery from toxicity, subsequent cycles were administered at reduced doses in 11 patients, and no additional delay or dose reduction was necessary. Of the 208 cycles given, 29(13.9\%) were administered at reduced doses.

Definitive withdrawn of treatment due to gr 3 peripheral neuropathy occurred in four patients (12\%) after $8,8,9$, and 10 cycles of GEMOX.

\section{Toxicity}

One toxic death was reported. This was due to febrile neutropenia that occurred after five cycles of GEMOX (without any previous haematologic toxicity). This patient did have a response to GEMOX after four cycles of treatment, but this was, of course, not confirmed and not considered as a PR.

Haematologic and nonhaematologic toxicities are described in Table 3.

One gr 4 toxicity was reported, consisting of febrile neutropenia that lead to the death of the patient. Gr 3 haematologic toxicities were observed in $8 / 33$ patients (24\%), consisting of neutropenia (3), anaemia (2), and thrombopenia (3). Gr 3 nonhaematologic toxicity occurred only in three patients (11\%): nausea (two patients) and vomiting (one patient).

Grade 1, 2, and 3 peripheral neuropathy were observed in $17(51 \%), 3(9 \%)$, and $4(12 \%)$ of 33 patients, respectively.

The total number of gr 3-4 toxicities recorded was 16 patients $(48 \%)$.

Overall, the regimen was well tolerated.

Table 3 Reported haematologic and nonhaematologic toxicities

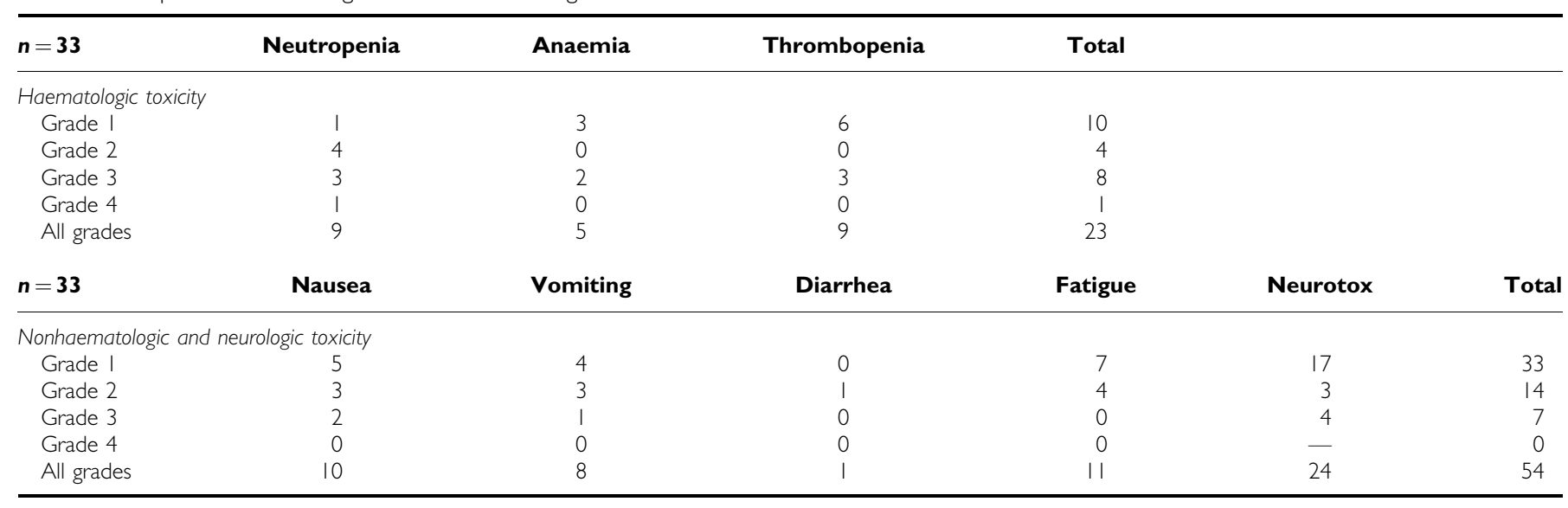

Reported haematologic and nonhaematologic toxicities. 


\section{Efficacy results}

Of the 33 patients, 31 were evaluable for response and clinical benefit response.

Seven patients $(22.6 \%)$ experienced a partial response (PR) that was confirmed, with a median duration of this response of 4.5 months (range 1.5-16).

In all, 12 patients (38.7\%) were stabilised (stable disease, s.d.), whereby s.d. endured for more than 8 weeks in 11 patients $(35.5 \%)$, and for $<8$ weeks in $1 / 31(3.2 \%)$.

Median TTP was 4.2 months. Median survival since the start of GEMOX was 6 months (range $0.5-21$ ). Median survival since the start of first-line treatment was 12 months (range 3-34).

A clinical benefit response was observed in 17 evaluable patients (54.8\%).

Regarding the 16 patients who had progressed within 3 months of previous first-line GEM, best responses were: $1 \mathrm{PR}, 5$ s.d. and 10 PD. Re-challenging this group of patients with GEMOX led to PR in $1 / 1,3 / 5$, and $3 / 10$, respectively, and s.d. in four additional patients.

\section{DISCUSSION}

The present study reports, for the first time, the use of the GEMOX regimen in gemcitabine-refractory, locally advanced and metastatic pancreatic adenocarcinoma. Currently, in gemcitabinerefractory patient, there is no data concerning the choice of the

Table 4 Comparison of toxicity profiles (values are expressed in \%)

\begin{tabular}{lccc}
\hline Toxicity (in \%) & $\begin{array}{c}\text { Demols } \\
\text { (second line) }\end{array}$ & Louvet (2) & Heinemann ( 1 0) \\
\hline Gr3 neuropathy & 12 & 19 & ND \\
Gr3-4 neutropenia & 12.5 & 14 & 5 \\
Gr3-4 anaemia & 6 & 8 & 0 \\
Gr3-4 & 9 & 17 & 15 \\
thrombopenia & & 11 & ND \\
Gr3-4 nausea and & 9 & & \\
vomiting & & & \\
\hline
\end{tabular}

Comparison of toxicity profiles (values are expressed in \%). ND: not determined. second-line therapy. For these patients, we chose to assess the GEMOX regimen based on its activity (28.7\%) and tolerability profile reported in first-line use (Louvet et al, 2005). The schedule of administration and infusion rate within our study were similar to previous preclinical and clinical data (Faivre et al, 1999; Tempero et al, 2003). We chose to include LAD, because our trial design was a feasibility phase II study, and not a phase III survival trial.

The tolerability of GEMOX is well assessed as 59\% of were considered to be in poor condition (PS 1-2), where no major toxicities were seen. Overall, treatment was well tolerated, and with the exception of one gr 3 neuropathy and one febrile neutropenia, no other toxic event led to treatment interruption. Acute haematologic toxicity was limited, consisting mainly in gr 3 anaemia, thrombopenia and neutropenia. One toxic death was reported due to a febrile neutropenia that occurred after five cycles of GEMOX without any previous haematologic toxicity during the four first administrations. Typical peripheral oxaliplatin-related neuropathy was noted: half of the patients experienced a gr 1 neurotoxicity and four patients (12\%) had developed gr 3 neuropathy leading to withdrawal of GEMOX treatment. In these four particular patients, GEMOX was stopped after 8, 8, 9, and 10 cycles, respectively. Globally, these toxicity data are comparable to those from other studies using GEMOX in first line (Table 4).

The activity of the regimen was good, achieving partial response in $22.6 \%$ of and disease stabilisation for more than 8 weeks in $35.5 \%$ of patients. This activity is comparable to that observed in first line by Louvet $(28.7 \%)$ and to that observed in second line using oxaliplatin $\left(50 \mathrm{mg} \mathrm{m}^{-2}\right.$ weekly)/LV/5-FU (Tsavaris et al, 2005). A 6-month survival can be expected in the setting of secondline therapy, as supported by the findings of this study and other phase II trials based with other drugs combinations (Table 5).

Manageable toxicity and good clinical benefit response rate were also important valuable findings of this trial.

Our data also suggest that the addition of oxaliplatin to gemcitabine may be active and effective, even after progression or failure under the latter drug. Currently, it is difficult to differentiate between the relative role of each drug in overcoming the tumour resistance to gemcitabine administered alone in a standard 30 -min regimen. The addition of oxaliplatin to gemci-

Table 5 Phase II and III trials in second-line therapy

\begin{tabular}{|c|c|c|c|c|c|}
\hline Regimen & Authors and phase & Number of patients & PR (\%) & s.d. (\%) & Median OS (weeks) \\
\hline OX & $\begin{array}{l}\text { Androulakis et al (2005) } \\
\text { Phase II }\end{array}$ & 18 & 0 & 16.7 & ND \\
\hline CPT-I I/ralitrexed vs ralitrexed & $\begin{array}{l}\text { Ulrich-Pur et al (2003) } \\
\text { Ramdomised II }\end{array}$ & 38 & $\begin{array}{r}16 \\
0\end{array}$ & $\begin{array}{l}N D \\
N D\end{array}$ & $\begin{array}{l}26 \\
17\end{array}$ \\
\hline Paclitaxel & $\begin{array}{l}\text { Oettle et al (2000) } \\
\text { Phase II }\end{array}$ & 18 & 5.5 & 27.7 & 17.5 \\
\hline Capecitabine/erlotinib & $\begin{array}{l}\text { Blaszkowsky et al (2005) } \\
\text { Phase II }\end{array}$ & 30 & 11 & 57 & 27 \\
\hline $\begin{array}{l}\text { OX/FA/5-FU } \\
\text { Vs BSC }\end{array}$ & $\begin{array}{l}\text { Oettle et al (2000) } \\
\text { Phase III }\end{array}$ & 46 & ND & ND & $\begin{array}{l}21 \\
10\end{array}$ \\
\hline GEMOX & $\begin{array}{l}\text { Demols } \\
\text { Phase II }\end{array}$ & 33 & 22.6 & 38.7 & 25 \\
\hline
\end{tabular}

Phase II and III trials in second-line therapy. BSC: best supportive care; ND: not determined. 
tabine on day 2 could explain this resensitisation of the tumour, but the slower rate of infusion of gemcitabine versus how it was administered in first-line might also play a role in this recovered activity. Additional data is needed to determine what gives GEMOX its incremental activity over GEM in second-line.

Results coming from the ECOG 6201 trial, comparing gemcitabine as a standard 30 -min infusion, gemcitabine at a fixed-dose rate, and the GEMOX regimen will determine the best way to administer gemcitabine. It is anticipated that this trial will also clarify the role of oxaliplatin when added to gemcitabine in chemonaive patients. The Louvet trial has shown a better activity profile of the combination of these drugs versus monotherapy, but has failed to demonstrate a clear statistically significant survival advantage. These results are key to determine the place of oxaliplatin in the management of advanced pancreatic cancer.

Recently, other data have suggested a beneficial role of oxaliplatin in second-line therapy using the OFF regimen (oxaliplatin/ folinic acid/5-FU $24 \mathrm{~h}$ ). The randomised CONKO 003 phase III trial

\section{REFERENCES}

Androulakis N, Syrigos K, Polyzos A, Aravantinos G, Stathopoulos GP, Mallas K, Vamvakas L, Georgoulis V (2005) Oxaliplatin for pretreated patients with advanced or metastatic pancreatic cancer: a multicenter phase II study. Cancer Invest 23(1): 9-12

Blaszkowsky LS, Hulke KH, Ryan DP, Clark JW, Meyerhardt J, Zhu AX, Lawrence C, Fuchs CS (2005) A phase II study of erlotinib in combination with capecitabine in previously treated patients with metastatic pancreatic cancer. Proc Am Soc Clin Oncol 2005: abstract 4099

Burris HA, Moore MJ, Andersen J, Green MR, Rothenberg ML, Modiano MR, Cripps MC, Portenoy RK, Storniolo AM, Tarassoff P, Nelson R, Dorr FA, Stephens CD, Von Hoff DD (1997) Improvements in survival and clinical benefit with Gemcitabine as first-line therapy for patients with advanced pancreas cancer: a randomized trial. J Clin Oncol 15: $2403-2413$

Faivre S, Raymond E, Woynarowski JM, Cvitkovic E (1999) Supraadditive effect of $2^{\prime}, 2^{\prime}$-difluorodeoxycytidine (gemcitabine) in combination with oxaliplatin in human cancer cell lines. Cancer Chemother Pharmacol 44(2): $117-123$

Heinemann V, Quietzsch D, Gieseler F, Gonnermann M, Schonekas H, Rost A, Neuhaus H, Haag C, Stoffregen C, Clemens M (2003) A phase III trial comparing gemcitabine plus cisplatin $v s$ gemcitabine alone in advanced pancreatic carcinoma. Proc Am Soc Clin Oncol 2003 abstract 1003

Louvet C, André T, Lledo G, Hammel P, Bleiberg H, Bouleuc C, Gamelin E, Flesch M, Cvitkovic E, de Gramont A (2002) Gemcitabine combined with oxaliplatin in advanced pancreatic adenocarcinoma: final results of a GERCOR multicenter phase II study. J Clin Oncol 20(6): $1512-1518$

Louvet C, Labianca R, Hammel P, Lledo G, Zampino MG, Andre T, Zaniboni A, Ducreux M, Aitini E, Taieb J, Faroux R, Lepere C, de Gramont A (2005) Gemcitabine in combination with oxaliplatin compared with gemcitabine alone in locally advanced or metastatic pancreatic cancer: results of a GERCOR and GISCAD phase III trial. J Clin Oncol 23(15): 3509-3516

Moore MJ, Goldstein D, Hamm J, Figer A, Hecht J, Gallinger S, Au K, Ding J, Christy-Bittel J, Parulekar W (2005) Erlotinib plus gemcitabine compared to gemcitabine alone in patients with advanced pancreatic cancer. A phase III trial of the National Cancer Institute of Canada Clinical Trials Group (NCIC-CTG). Proc Am Soc Clin Oncol 2005: abstract 1

Ng M, Norman AR, Cunningham D, Waters J, Oates J, Ross P (2005) Phase II trial evaluating a 2 weekly regimen of irinotecan (IR) and 5-FU/ leucovorin (LV) in patients with metastatic pancreatic cancer refractory to chemotherapy. Proc Am Soc Clin Oncol 2005: abstract 4229 showed a statistically significant increase in overall survival when giving OFF regimen in second line, as compared to best supportive care (Oettle et al, 2005).

Nonetheless, many issues remain unanswered in the management of pancreatic cancer. The need to determine prognostic and predictive factors is essential to identify the best therapy for all patients. The emergence of biological therapies will, in fact, require such a prospective selection of patients based on these factors. The combination of new biological agents with another cytotoxic, such as oxaliplatin to gemcitabine could become a treatment standard. In the setting of second-line therapy, a prospective well-designed phase III trial would be useful to validate oxaliplatin-based regimens. In this setting, GEMOX could be compared to BSC, or to another oxaliplatin-based regimen; FOLFOX for example.

Our study, showing that the GEMOX regimen is active and well tolerated after progression with standard gemcitabine therapy, supports the beneficial role of this combination in advanced pancreatic cancer.
Oettle H, Arnold D, Esser M, Huhn D, Riess H (2000) Paclitaxel as weekly second-line therapy in patients with advanced pancreatic carcinoma. Anticancer Drugs 11(8): 635-638

Oettle H, Pelzer U, Stieler J, Hilbig A, Roll L, Schwaner I, Adler M, Detken S, Dörken B, Riess H (2005) Oxaliplatin/folinic acid/5-fluorouracil (24 h) (OFF) plus best supportive care versus best supportive care alone (BSC) in second line therapy of gemcitabine-refractory advanced pancreatic cancer (CONKO 003). Proc Am Soc Clin Oncol 2005: abstract 4031

O’Reilly EM, Abou-Alfa GK, Letourneau R, Harker WG, Modiano M, Hurwitz H, Tchekmedyian NS, Ackerman J, De Jager RL, Eckhardt G (2004) A randomized phase III trial of DX-8951f (exatecan mesylate; DX) and gemcitabine (GEM) vs gemcitabine alone in advanced pancreatic cancer (APC). Proc Am Soc Clin Oncol 2004: abstract 4006

Richards DA, Kindler HL, Oettle H, Ramanathan RK, Van Laethem J-L, Peeters M, Fuchs M, John W, Arning M, Von Hoff D (2004) A randomized phase III study comparing gemcitabine+pemetrexed versus gemcitabine in patients with locally advanced and metastatic pancreas cancer. Proc Am Soc Clin Oncol 2004: abstract 4007

Rocha Lima CMS, Green MR, Rotche R, Miller Jr WH, Jeffrey GM, Cisar LA, Morganti A, Orlando N, Gruia G, Miller LL (2004) Irinotecan plus gemcitabine results in no survival advantage compared with gemcitabine monotherapy in patients with locally advanced or metastatic pancreatic cancer despite increased tumor response rate. J Clin Oncol 22(18): $3376-3383$

Tempero M, Plunkett W, Ruiz Van Haperen V, Hainsworth J, Hochster H, Lenzi R, Abbruzzese J (2003) Randomized phase II comparison of dose-intense gemcitabine: thirty-minute infusion and fixed dose rate infusion in patients with pancreatic adenocarcinoma. J Clin Oncol 21(18): $3402-3408$

Therasse P, Arbuch SG, Eisenhower EA, Wanders J, Kaplan RS, Rubinstein L, Verweij J, Van Glabbeke M, van Oosterom AT, Christian MC, Gwyther SG (2000) New guidelines to evaluate the response to treatment in solid tumors. J Natl Cancer Inst 92: 205-216

Tsavaris N, Kosmas C, Skopelitis H, Gouveris P, Kopteridis P, Loukeris D, Sigala F, Zorbala-Sypsa A, Felekouras E, Papalambros E (2005) Secondline treatment with oxaliplatin, leucovorin and 5-fluorouracil in gemcitabine-pretreated advanced pancreatic cancer: a phase II study. Invest New Drugs 23(4): $369-375$

Ulrich-Pur H, Raderer M, Verena Kornek G, Schull B, Schmid K, Haider K, Kwasny W, Depisch D, Schneeweiss B, Lang F, Scheithauer W (2003) Irinotecan plus ralitrexed $v s$ ralitrexed alone in patients with gemcitabine-pretreated advanced pancreatic adenocarcinoma. Br J Cancer 88(8): $1180-1184$ 